\title{
Behavioural and physiological mechanisms behind extreme longevity in Daphnia
}

\author{
Barbara Pietrzak • Anna Bednarska • \\ Magdalena Markowska • Maciej Rojek • \\ Ewa Szymanska $\cdot$ Miroslaw Slusarczyk
}

Received: 31 March 2012/ Accepted: 1 December 2012/Published online: 28 December 2012

(C) The Author(s) 2012. This article is published with open access at Springerlink.com

\begin{abstract}
The combined effect of external environment and energy allocation strategy of the organism on longevity can be exceptional. In a cold oligotrophic fishless habitat, individual Daphnia can live for over a year, several times the usual Daphnia lifespan. This extreme lifespan is in part a consequence of the overwintering strategy which includes storing resources and delaying reproduction until another spring. Yet, contrasting strategies may be applied by Daphnia, resulting in over twofold differences in lifespan within a single habitat. We identify physiological mechanisms mediating such differences in longevity in closely related Daphnia of two lineages coexisting within a high altitude lake, testing the predictions that long-lived animals stay in colder waters and have lower metabolic rates, irrespective of temperature. Vertical distribution
\end{abstract}

Guest editors: Marina Manca \& Piet Spaak / Cladocera: Proceedings of the 9th International Symposium on Cladocera

B. Pietrzak $(\bowtie) \cdot$ A. Bednarska $\cdot$ M. Rojek ·

E. Szymanska $\cdot$ M. Slusarczyk

Department of Hydrobiology, University of Warsaw,

Banacha 2, 02-097 Warsaw, Poland

e-mail: b.pietrzak@uw.edu.pl

B. Pietrzak

Max Planck Institute for Demographic Research,

Konrad-Zuse-Strasse 1, 18057 Rostock, Germany

M. Markowska

Department of Animal Physiology, University of Warsaw,

Miecznikowa 1, 02-096 Warsaw, Poland of the animals was assessed during three summer stratification seasons, and metabolic activity was measured as oxygen consumption and RNA:DNA ratio. The results not only support our predictions but also reveal that habitat choice is dependent on reproductive status rather than genotype. The young individuals of the overwintering lineage may delay reproduction in part by staying in colder waters than the reproducing adults, which together with low intrinsic metabolic rates may underlie the longevity of Daphnia of this lineage.

Keywords Daphnia - Life-history · Longevity · Metabolic activity $\cdot$ Habitat choice .

Diel vertical migration $\cdot$ Alpine lake

\section{Introduction}

In lakes and ponds of the temperate zone, life cycle of most planktonic cladoceran species is short and in the order of weeks (Threlkeld, 1987). This may be a result of selection by temporarily changing abiotic conditions: drying or overfreezing in shallow habitats, or oxygen deficits in deep lakes of high trophic level. This is also in part a consequence of fish predation pressure acting as a strong selective force under which probability of surviving to subsequent reproductive period is low, and thus Daphnia follow the $r$ strategy, maximizing fitness by investing in early reproduction (Threlkeld, 1979; Boersma et al., 1998; Pijanowska et al., 2006; Dawidowicz et al., 2010). In deep 
oligotrophic habitats with no oxygen deficits, where fish predation pressure is reduced or absent, released from the selective pressure on early reproduction, Daphnia can maximize fitness by applying different strategies, including those involving the delay of the onset of reproduction and lengthening the lifespan (Dawidowicz et al., 2012). This is possible at the concurrent permanence and stability of the habitat, which favour the evolution of longevity (Pianka, 1970; Grime, 1977).

Indeed, exceptionally long lifespan combined with a biennial life cycle has been found in Daphnia from high altitude or latitude fishless lakes (Gliwicz et al., 2001; Larsson \& Wathne, 2006; Slusarczyk, 2009). Where it was found, this strategy of overwintering in the water column and delaying reproduction until the second breeding season coexisted with a contrasting strategy: that of winter diapause in the form of resting eggs, produced parthenogenetically. The situation in deep oligotrophic fishless Czarny Staw pod Rysami in the High Tatra Mountains is an example. The lake is inhabited by cladocerans of two distinct lineages belonging to one species: European Daphnia pulicaria clade within tenebrosa group of Daphnia pulex species complex (Dufresne et al., 2011; R. Vergilino, personal communication). At least one of the lineages reproduces exclusively by obligate parthenogenesis (Dufresne et al., 2011), which prevents interbreeding. In each of the High Tatra lakes inhabited by these two lineages, they either coexist or occur alone, but no more than a few genotypes (clones) are found together, and not more than two are found dominating, these differing in overwintering mode (Černý \& Hebert, 2011). Individuals of these two lineages differ conspicuously in the colouring of the fat reserves, which gives them either a transparent or an orange appearance. Indeed, the occurrence of two Daphnia colour morphs was recorded in Czarny Staw as long as a century ago (Minkiewicz, 1911). The quality of the fat stores appears meaningful, as these two differ in the way they manage and expend the very limited resources, and as such-in their overwintering strategy and consequently, in longevity (Gliwicz et al., 2001; Slusarczyk, 2009).

Individuals of the 'transparent', exclusively asexual, lineage complete their life cycle in the water column within one growing season. They hatch from parthenogenetic resting eggs in spring and begin reproduction after a relatively short period of growth; in late summer, they produce, or their offspring produce, parthenogenetic resting eggs and die soon. The population survives winter only as the diapausing eggs, and thus the individual post-hatching lifespan does not exceed 5-6 months in these annual animals (Slusarczyk, 2009). The exceptionally long-lived individuals of the 'orange' lineage do not produce resting eggs in Czarny Staw though genetic data do not exclude their occasional sexuality (Dufresne et al., 2011; M. Slusarczyk \& J. Mergeay, unpublished data). They follow a capital breeding strategy with delayed reproduction in a biennial cycle. They do not reproduce during their first season, when they were born, but grow, acquire and store resources to survive the winter in the water column and begin reproduction the following spring. Their individual lifespan can reach 13-14 months. As a consequence, in summer, there are three easily distinguishable groups of animals present in the lake: (i) the young-of-the-year from the biennial, overwintering 'orange' lineage, (ii) the previous year born, reproducing individuals from this biennial lineage and (iii) individuals of the annual, ephippia-producing 'transparent' lineage (Slusarczyk, 2009).

These life histories have most probably diverged as a result of conflicting selective pressures acting on energy allocation into either soma or reproduction (Stearns, 1992). However, this may have been followed by and have additional grounds in more mechanistic differences in the use of energy. According to the classical rate-of-living theory, individual lifespan depends on the rate of energy expenditurerate of metabolism, and on genetically determined amount of energy consumed in adult life-metabolic potential (Sohal et al., 2002). As metabolic potential is similar in closely related species (Speakman, 2005), it can be expected that the twofold differences in Daphnia lifespan of two closely related, coexisting lineages will be associated with different metabolic rates. Such differences can be grounded both genetically and environmentally.

Temperature is one of the most important environmental factors strongly influencing energetic demand. In ectotherms, lower temperature naturally leads to lowering metabolic rates and lengthening of lifespan (Miquel et al., 1976; McArthur \& Sohal, 1982; Leiser et al., 2011), which has also been observed in Daphnia (MacArthur \& Baillie, 1929; Orcutt \& Porter, 1984). In thermally stratified lakes, lower temperatures are 
experienced by animals staying in deeper layers, thus a single lake presents planktonic animals with a gradient of thermally different habitats, and several studies have shown that populations may segregate between these. This includes large and small individuals of the same species having different migratory behaviours (Kessler, 2004; Kessler \& Lampert, 2004; Reichwaldt \& Abrusán, 2007; Reichwaldt, 2008), as a consequence of their having different optimal habitats (Reichwaldt \& Abrusán, 2007).

Apart from differences implicated by habitat choice, the animals of the long- and short-lived lineage might differ in their metabolic activity irrespective of the environmental temperatures. A widely used method for assessing metabolic rate in laboratory conditions is the oxygen consumption measurement (Wieser et al., 1992; Houthoofd et al., 2002), whereas RNA:DNA ratio has been used in different organisms as an indicator of physiological condition and metabolic activity in the field (Wagner et al., 1998; Meesters et al., 2002; Cullen et al., 2003; Buckley \& Szmant, 2004). Under laboratory conditions, the latter has also been shown as an indicator of growth (Zhou et al., 2001; Ibiam \& Grant, 2005), dependent on the developmental stage of the animal (Gorokhova \& Kyle, 2002; Ibiam \& Grant, 2005).

The aim of this study was to identify mechanisms underlying the extreme differences in longevity in the closely related Daphnia of the two lineages coexisting within the lake. We tested the hypotheses that the observed differences in life histories, and in lifespan in particular, (i) are mediated by habitat choice in the vertical gradient of temperature, and (ii) that they are also a consequence of differences in basic physiology-metabolic rates. We thus predicted the shortlived Daphnia (i) to stay on average in shallower, warmer waters and (ii) to have higher metabolic rates measured as oxygen consumption and RNA:DNA ratio, than the long-lived Daphnia.

\section{Methods}

We assessed vertical distribution of $D$. pulicaria in Czarny Staw pod Rysami (1,581 $\mathrm{m}$ above sea level) in the High Tatra Mountains in Southern Poland. The animals were sampled at the time of summer stratification, in August of three different years (1999, 2003 and 2010), during the day and at night each year. Stratified live samples were taken in vertical hauls using a quantitative Apstein closing plankton net (150$\mu \mathrm{m}$ mesh size) from discrete 5-m (surface layers) or 10-m (deeper layers) strata, covering the whole water column at the deepest spot of the lake. The net was equipped with a long collar and a separately operated closing line attached to the largest ring of the net to prevent loss or admixture of individuals from different strata (de Bernardi, 1984; Masson et al., 2004). Quantitative subsamples were analysed under dissecting microscope. Daphnia of three groups were counted: (i) short-lived individuals of the ephippiaproducing lineage and the long-lived: (ii) young and (iii) adult individuals (born in the year of sampling or the previous year, respectively) of the overwintering lineage. The counts were used to calculate the density of the animals at different depths. Temperature and oxygen profiles were taken at each plankton sampling date and the mean temperature of each layer from which the animals were taken was estimated. In the first sampling year (1999), 21 water samples were taken from depths between 5 and $65 \mathrm{~m}$, each $10 \mathrm{~m}$, and filtered through glass-fibre filter $(30 \mu \mathrm{m})$ to measure particulate organic carbon content (Wetzel \& Likens, 1991). In 2003, chlorophyll $a$ concentration in water samples taken from mid-depth of each layer from which zooplankton samples were taken was determined fluorometrically (Turner Designs) (Welschmeyer, 1994).

Comparisons between the three groups (i.e. including the age class discrimination in the biennial, Table 1) were made for all 3 years on weighted mean depths (Basedow et al., 2010, Ringelberg, 2010) and weighted mean temperatures at which animals of the three groups resided at the times of sampling, both measures correcting for the different widths of the sampled strata. ANOVA was performed, followed by between group comparisons with post hoc Tukey's test at $\alpha=0.05$.

As physiological assays were meant to be measures of intrinsic processes, independent of the temperature of the environment, the samples for nucleic acids ratio analysis and for oxygen consumption experiment were taken from Czarny Staw at a time point when temperature in the water column was close to uniform, at the beginning of the autumnal mixing. Daphnia for these assays were taken from a single layer, 15-25 m depth, in 2010, when temperature in the water column 
Table 1 Summary of the results for the three groups of D. pulicaria from Czarny Staw

\begin{tabular}{lllc}
\hline & Short lived & Long-lived young (1st year) & Long-lived adults (2nd year) \\
\hline Lineage & Ephippia producing (annual, 'transparent') & Overwintering (biennial, 'orange') \\
Stage & Reproductive & Juvenile & Reproductive \\
Size $(\mathrm{mm})$ & 1.6 & 1.7 & 3.0 \\
Depth $(\mathrm{m})$ & $14.3 \pm 2.8$ & $24 \pm 2.6$ & $14.5 \pm 2.3$ \\
Temp. $\left({ }^{\circ} \mathrm{C}\right)$ & $8.4 \pm 0.6$ & $6.2 \pm 0.4$ & $8.1 \pm 0.7$ \\
OC $\left(\mathrm{mgO}_{2} \mathrm{mg}^{-1} \mathrm{day}^{-1}\right)$ & $0.089 \pm 0.009$ & $0.074 \pm 0.001$ & $0.076 \pm 0.004$ \\
RNA:DNA & $33.8 \pm 1.4$ & $27.5 \pm 1.4$ & $30.2 \pm 2.1$ \\
\hline
\end{tabular}

Size averaged size of Daphnia in August-September, given according to Slusarczyk (2009); Depth weighted mean depth; Temp. weighted mean temperature at which animals resided, averaged over all sampling times; OC oxygen consumption. Mean \pm SE. Group effect was significant for all measured parameters, see details in text

ranged from $7^{\circ} \mathrm{C}$ at the surface to $4^{\circ} \mathrm{C}$ at the bottom. 24 individuals of each of the three studied groups were separated straight from the plankton samples, transferred to $1.5-\mathrm{ml}$ tubes, flash frozen in liquid nitrogen on site and later stored at $-85^{\circ} \mathrm{C}$ until RNA:DNA analysis. After having been sampled from the water column, Daphnia used in the oxygen consumption experiment were acclimated for $6 \mathrm{~h}$ and the experiment was performed at $12^{\circ} \mathrm{C}$, surface temperature in Czarny Staw that summer. 10 individuals of each group were placed in 50-ml vials of aerated Czarny Staw water, all in six replicates (3 groups $\times 10$ individuals $\times 6$ vials $=180)$. Oxygen concentration was recorded with a ProOdo optic probe (YSI) while filling the vials, which were then capped under the water surface with care taken not to close any air bubbles inside, and the second oxygen recording was done after $14 \mathrm{~h}$ of exposure. Four individuals from each vial were dried and weighed.

RNA and DNA were extracted and analysed using the fluorochrome RiboGreen in combination with RNase treatment according to a modified protocol of Vrede et al. (2002). To each 1.5-ml tube containing one Daphnia individual, $200 \mu \mathrm{l}$ of TE buffer was added and the animal was homogenized with an RNase-free plastic pellet pestle. Thereafter, the samples were vortexed on a microplate shaker (15 min, $\left.4^{\circ} \mathrm{C}, 900 \mathrm{rpm}\right)$, sonicated $3 \times 10 \mathrm{~s}$ in ice water, vortexed again $\left(5 \mathrm{~min}, 4^{\circ} \mathrm{C}, 900 \mathrm{rpm}\right)$ and centrifuged $\left(5 \mathrm{~min}, 4^{\circ} \mathrm{C}, 15700 \times g\right)$. Supernatants were transferred into new $1.5-\mathrm{ml}$ tubes and diluted 1:3 with the TE buffer. Duplicate or triplicate $100 \mu \mathrm{l}$ subsamples were transferred to a black 96-well microplate, 2,000 time diluted fluorochrome RiboGreen (Molecular Probes) reagent solution $(100 \mu \mathrm{l})$ was added and the samples were gently mixed for $5 \mathrm{~min}$ in darkness. Fluorescence was then measured in a spectrofluorometer using a microplate reader (Victor 3, Perkin Elmer) at 485-nm excitation wavelength and 535-nm emission wavelength. After the first fluorescence measurements, $26 \mu \mathrm{l}$ RNase solution (1.8 Kunitz, ribonuclease A from bovine pancreas; Sigma) was added to all samples, microplate was incubated on the microplate shaker (20 min, room temperature, $300 \mathrm{rpm}$ ), and fluorescence was subsequently measured as above. To estimate the contribution of DNA in the samples, the fluorescence after RNA digestion was subtracted from the total fluorescence before RNase treatment, and subsequently RNA:DNA ratio was calculated. For details on buffers and solutions preparation, see Vrede et al. (2002). All Daphnia used for oxygen consumption and RNA:DNA assays were either juveniles or females bearing subitaneous eggs.

\section{Results}

The mean midsummer densities of Daphnia in the water column throughout the study period were $145 \pm$ 35 ind. $\mathrm{m}^{-3}$ of the annuals and $483 \pm 169$ ind. $\mathrm{m}^{-3}$ of the biennials, and the relative abundance of the first to second year individuals of the latter lineage was about 10:1. The vertical distribution of the animals in the water column differed between groups.

There were significant effects of group, time of day and year on the depth at which Daphnia stayed in the lake (three-way ANOVA, group effect: $F_{2,17}=41.24$, $P=0.0003$, time of day effect: $F_{2,17}=22.84, P=$ 0.0031 , year effect: $F_{2,17}=41.50, P=0.0282$; All 
two-way and three-way interactions were not significant $(P>0.069))$. Young individuals of the biennial, overwintering lineage stayed on average deeper than both the reproducing adults of the same lineage and than Daphnia of the annual, ephippia-forming lineage (Table 1; Fig. 1). The animals stayed deeper during the day than at night $(20.0 \pm 2.2 \mathrm{~m}$ vs. $15.2 \pm 2.7 \mathrm{~m}$ (mean $\pm \mathrm{SE}$ ), respectively) and at different depth each year $(16.7 \pm 2.6 \mathrm{~m}$ in $1999,23.5 \pm 3.1 \mathrm{~m}$ in 2003 , and $12.5 \pm 1.8 \mathrm{~m}$ in 2010). The differences in vertical distributions were similarly meaningful when translated into temperatures of occurrence (temperature and food concentration profiles are presented in Fig. 2). There was a significant effect of group (threeway ANOVA, $\left.F_{2,17}=18.43, P=0.0027\right)$, time of day $\left(F_{2,17}=25.12, P=0.0024\right)$ and year $\left(F_{2,17}=\right.$ $6.91, P=0.0277)$ on the mean temperature at which the animals were found (Fig. 3). All two-way and three-way interactions were not significant $(P>0.06)$. Accordingly with the differences in depth, young biennials stayed in colder waters than both the reproducing adults of the same lineage and than the annuals (Table 1; Fig. 3). The animals stayed in colder water during the day than at night $(6.8 \pm$ $0.4^{\circ} \mathrm{C}$ vs. $8.4 \pm 0.6^{\circ} \mathrm{C}$ (mean $\pm \mathrm{SE}$ ), respectively) and in colder water in 2003 than in $2010\left(7.0 \pm 0.8^{\circ} \mathrm{C}\right.$ vs. $8.4 \pm 0.4^{\circ} \mathrm{C}$, respectively). In addition, neither lineage nor size had an effect on mean depth or temperature of occurrence. Significant effect of stage (reproductive vs. juvenile) on mean depth was seen (one-way ANOVA, $F_{2,17}=9.75, P=0.0066$ ), juvenile individuals staying deeper than the reproductive ones $(24.0 \pm 2.6$ vs. $14.4 \pm 1.8 \mathrm{~m})$.

Both assays returned parallel results on metabolic activity. Oxygen consumption per mass differed between the three groups of animals (one-way ANOVA, $\left.F_{2,17}=5.92, P=0.0127\right)$ and was higher in the annuals than in the overwintering Daphnia of both ages (Table 1; Fig. 4). RNA:DNA ratio also differed between these groups (one-way ANOVA, $F_{2,61}=$
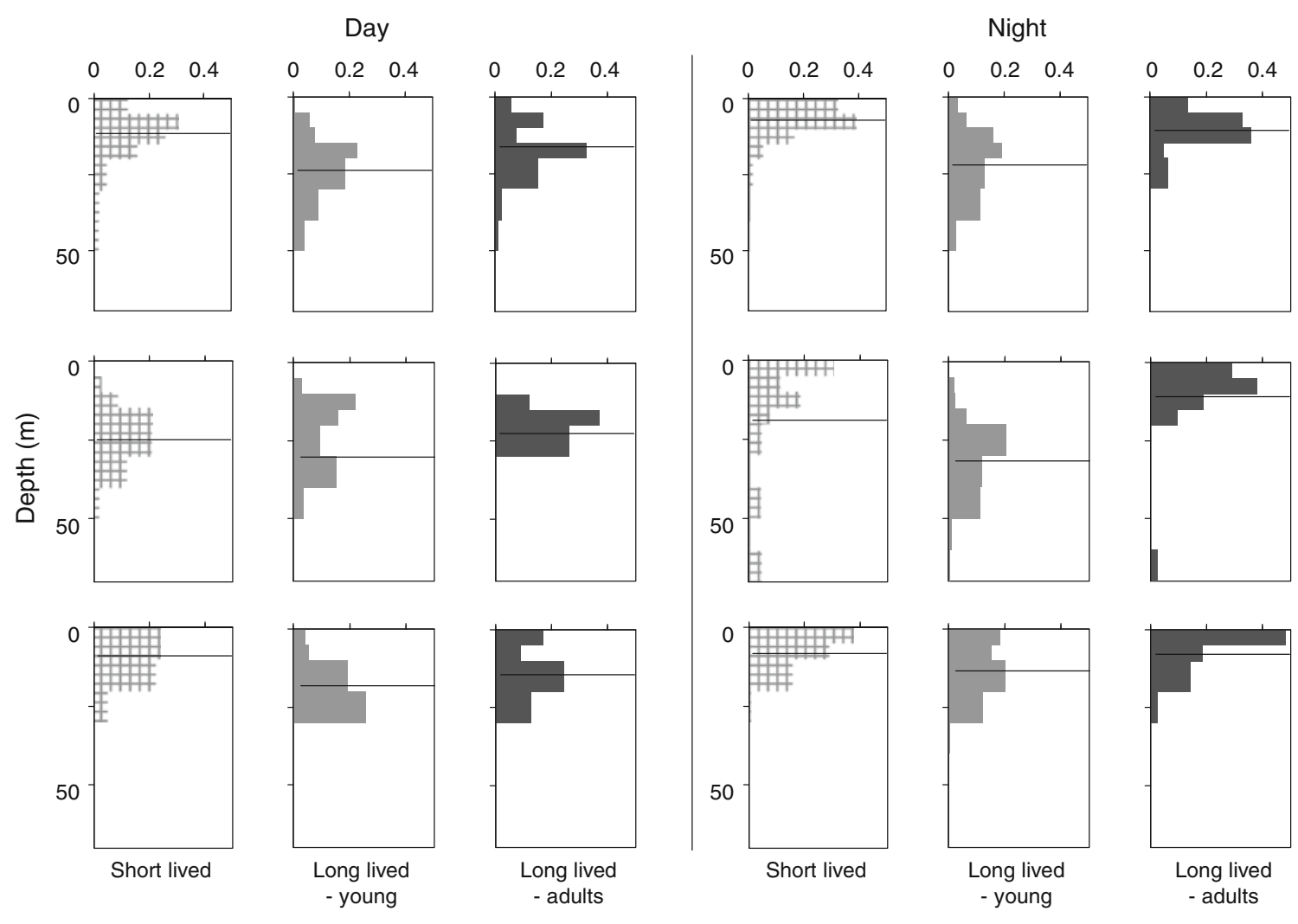

1999
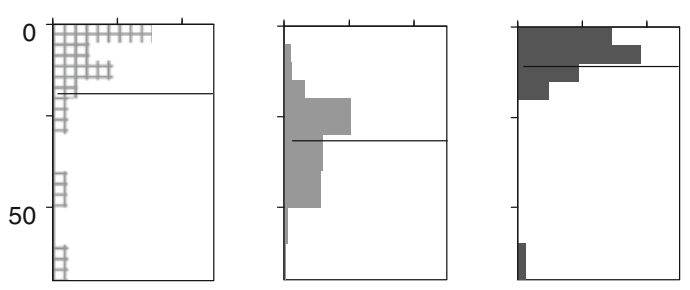

2003
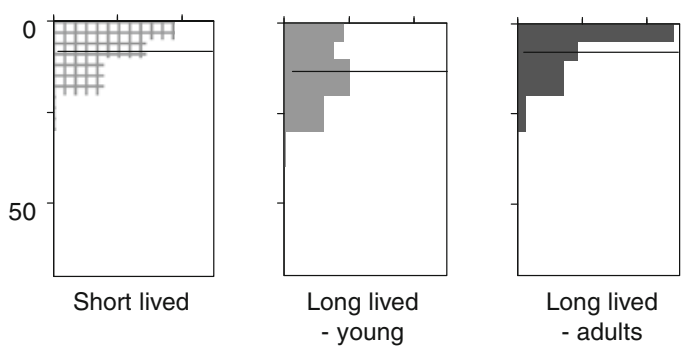

2010

Fig. 1 Day and night vertical distribution of D. pulicaria presented as the share of the group population present in the water column of Czarny Staw. Horizontal lines mark the weighted mean depth 
Fig. 2 Temperature (left) and food concentration (right) profiles in Czarny Staw at the times of sampling. In 1999, food concentration was measured as organic carbon; in 2003, as chlorophyll $a$ content; for 2010 , no data is available

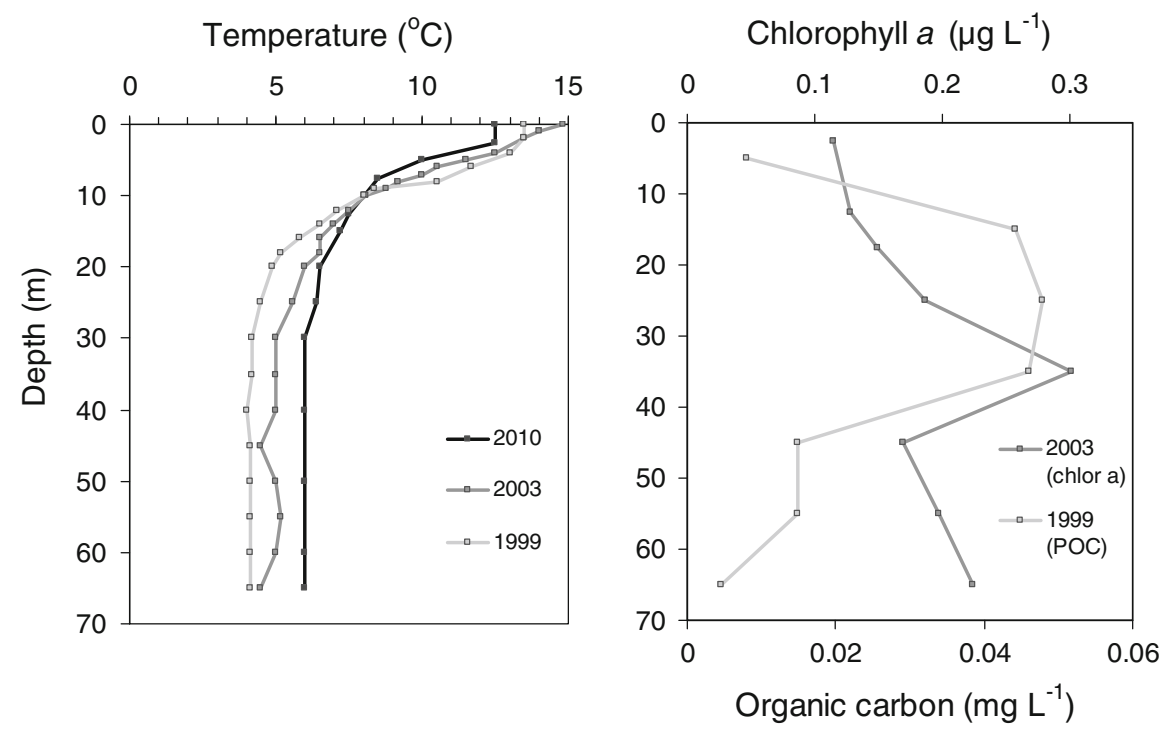

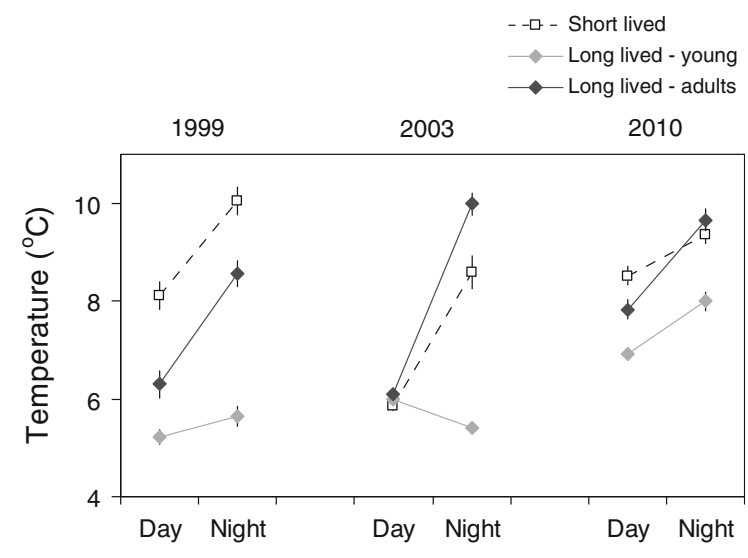

Fig. 3 Weighted mean temperature at which D. pulicaria stayed in Czarny Staw (data for 3 years, mean $\pm \mathrm{SE}$ )

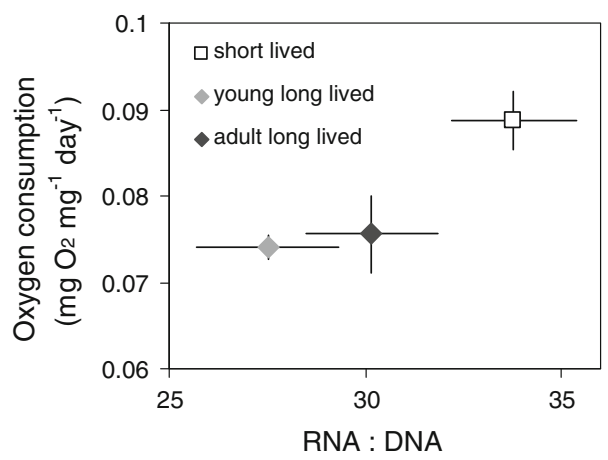

Fig. 4 Metabolic activity of $D$. pulicaria of the three studied groups as measured by RNA:DNA ratio and oxygen consumption (mean $\pm \mathrm{SE}$ )
3.47, $P=0.0376$ ), and was significantly higher in the ephippia producing than in the young overwintering Daphnia only (Table 1; Fig. 4).

\section{Discussion}

Temperature governs metabolism through its effect on the rate of biochemical reactions, and the rate of metabolism observed at the level of the organism increases exponentially with temperature (Gillooly et al., 2001). In high altitude or latitude oligotrophic lakes, Daphnia are faced with very low temperatures all season long. Low temperatures naturally extend cladoceran lifespan through lowering metabolic rates, and this lengthening is reinforced by very low concentrations of food. Such conditions, together with the length of the growing season strongly limited by long periods of ice cover, demand strategies of surviving winter other than those effective in lowland lakes. Two possible strategies enable planktonic species surviving in time constrained habitats, where the temperatures do not allow for more than two or three generations, and food conditions secure reproductive success only early in the season (Edmondson, 1955; Stross \& Kangas, 1969; Larsson \& Wathne, 2006). The first is the early reproduction and shortening the life cycle through obligatory parthenogenesis and production of resting eggs even by the first generation that hatches in spring. The second is 
delaying reproduction while accumulating resources to survive winter in the water under the ice cover and reproduce early in the second growing season.

The aim of this study was to test the hypothesis that the observed differences in life histories, and in lifespan in particular, are mediated by habitat choice of Daphnia representing two coexisting strategies. As in a thermally stratified lake, faster growth and development are feasible in the layers closer to the surface, and slowed down in the deeper layers, we hypothesized that individuals of the short-lived annual lineage stay closer to the surface than the long living individuals of the overwintering biennial one-the former shortening, the latter lengthening developmental time.

The results obtained stay in accordance with this 'rate-of-living' hypothesis (Pearl, 1928). Analysis of the plankton samples collected from the cold lake in the summer showed that young individuals of the biennial lineage stayed on average deeper in the water column than the reproducing adults of the same lineage and than the shorter-lived individuals of the ephippia forming lineage. In consequence, the young biennials chose on average $\sim 2^{\circ} \mathrm{C}$ colder water than the animals of the other two groups-considerable difference, taking into account low and narrow range of temperatures in the lake. The animals migrated between the colder and warmer waters on diurnal basis. Such migratory behaviour, i.e. avoiding surface waters during the day, observed in the absence of fish is most probably caused by ultraviolet radiation, an important factor shaping zooplankton vertical distribution in high altitude or latitude ultraoligotrophic habitats (Tartarotti et al., 1999; Rhode et al., 2001; Williamson et al., 2001), preventing the animals from fully profiting from higher temperatures in the subsurface water during daylight hours. The between-year variability in depth and temperature distribution is interrelated, depth of occurrence being influenced by temperature profile and other resulting physical and biotic gradients in the lake. The pronounced differences in both depth and temperature distribution between 2003 and 2010 may be partly due to differences in light conditions on the dates of sampling, sunny versus overcast, respectively (data not presented; weather record not available for 1999), which strengthened the between day and night differences.

The fact that the first and second year individuals of the overwintering lineage stayed at different depths reveals that the depth selection behaviour of these animals is not only genotype but also age or stage dependent. Juveniles of the biennials appeared to delay the onset of reproduction by staying in colder waters than the reproductively active adults of both lineages. It seems also that the young individuals of the overwintering lineage, staying deepest $(24 \mathrm{~m}$ on average), were more influenced by algal distribution in the water column than were the other two groups: the highest food concentrations were observed 25-35-m down. Indeed, food threshold concentrations are higher for small or young Daphnia (Gliwicz, 1990; Kreutzer, 1999). The observed distribution could be an example of a niche segregation resulting from inter- or intraspecific competition for food between small and large sized individuals, if the vertical distribution of the animals was size dependent. However, the equally small sized individuals of the ephippia-producing lineage were staying in most cases in food poor surface waters, together with the large adults of the overwintering lineage. Vertical distribution of the animals was neither size nor lineage, but stage, i.e. reproductive status, dependent.

The young Daphnia of the overwintering lineage may delay reproduction in part by staying in deeper, colder, although richer in food waters, but then as adults they move to higher temperatures to shorten the development time of the eggs they bear and to produce another clutch of offspring before the food resources are depleted. Daphnia of the ephippial lineage stay in warmer waters throughout the free-swimming part of their life cycle, which enables them to complete reproduction within one season. This suggests that the two lineages of Daphnia achieve such different life histories, both through differences in energy allocation and through manipulating their metabolism through behavioural thermoregulation.

Daphnia of the studied lineages differ in their early reproductive investments. Although the youngof-the-year of both lineages attain similar body size during the growing season, only individuals of the ephippia-producing lineage begin to reproduce that same season, which is within the first 2 months of their life (Slusarczyk, 2009). Individuals of the same age and size, but belonging to the other lineage, delay reproduction for almost a year, investing the scarce resources in accumulating energy reserves and in further growth instead. Allocating energy into soma means investing in the increased probability of survival and future reproduction (Kozłowski, 1993). 
Allocating these limited resources into reproduction means the loss of this energy to maintaining the soma, storing resources or further growth. At the end of the growing season, individuals of the ephippia-producing lineage are smaller than the current year individuals, now the only individuals of the overwintering lineage left in the water column. The annuals are deprived of fat stores after the reproductive season, the reserves being put into ephippia production, and soon disappear from the water column (Slusarczyk, 2009).

We expected that the differences in lifespan are not only mediated by habitat choice but also by differences in basic physiology, the short-lived Daphnia having higher metabolic activity measured as oxygen consumption and RNA:DNA ratio than Daphnia of the long-lived lineage when assayed at the same temperature.

Indeed, the measurement of metabolic activity revealed lower oxygen consumption in both young and adult individuals of the long-lived overwintering lineage than those of the ephippia-producing lineage. This finding stays in accordance with the expectations linking longevity to the rate-of-living. Oxygen consumption assessed several hours after taking animals from the lake, after acclimation and the duration of the experiment yielded results similar to metabolic activity measured through the RNA:DNA ratio in animals taken straight from the lake. In the latter, though, a significant difference was seen only between the annuals and young biennials. That the annuals had the highest and the young biennials the lowest RNA:DNA ratio might confirm the usefulness of this measure as a metabolic activity indicator. However, it also indicates that inferring nutritional condition upon this measure (Wagner et al., 1998) might not be straightforward, as depending on current energy allocation pattern in the organism. Our results suggest the nucleic acid ratio could rather be used as an indicator of reproductive status in the field, as it was lower in juveniles than in egg-carrying females, clearly due to RNA:DNA ratio being the highest in developing embryos (Gorokhova \& Kyle, 2002).

As oxygen consumption was lineage dependent and lower in the biennials than in annuals, the results of the present study suggest that lower intrinsic metabolic rates of the biennials, together with the staying deeper in the water column of their young, may be their strategy for longevity. The observed lowest transcriptional activity in the young biennials could then be a consequence of that strategy and a direct result of delayed reproduction. Although single time point measurements preclude whole-season generalisations, the above results were obtained for the end of summer/early fall, when water mixing started. This is the time when the young individuals of the biennials finish accumulating resources before overwintering, and the last surviving second-year adults of this lineage disappear from the water column (Slusarczyk, 2009). At the same time, many of the annuals, more metabolically active according to our results, are still reproductively active and carry ephippium.

In summary, our data indicate that both behavioural and physiological mechanisms underlie the extreme differences in longevity in these closely related Daphnia and the exceptionally long lifespan of the overwintering ones. Further studies could verify these conclusions through the measurement of seasonal dynamics in metabolic activity in these animals, their sensitivity to changes in temperature and identifying possible additional effects of food availability and distribution. Such studies would also help in identifying the mechanisms underlying apparently stable, over 100 years in the case of Czarny Staw, coexistence of two closely related lineages within a habitat.

Acknowledgments We would like to thank Jaromír Seda and an anonymous reviewer for valuable comments that helped improve the manuscript, Joanna Pijanowska for discussions on the topic, Martin Černý and Roland Vergilino for discussing lineages phylogeny, and Adam Ciepliński for help with field work. The study was supported by Polish Ministry of Science and Higher Education grant 2 P04F 06927 to M. Ślusarczyk, and Polish Ministry of Science and Higher Education grant IP 2010 031670 and University of Warsaw, Faculty of Biology intramural grant 191125 to B. Pietrzak.

Open Access This article is distributed under the terms of the Creative Commons Attribution License which permits any use, distribution, and reproduction in any medium, provided the original author(s) and the source are credited.

\section{References}

Basedow, S. L., K. S. Tande \& L. C. Stige, 2010. Habitat selection by a marine copepod during the productive season in the Subarctic. Marine Ecology Progress Series 416: 165-178.

Boersma, M., P. Spaak \& L. De Meester, 1998. Predator-mediated plasticity in morphology, life history, and behavior of Daphnia: the uncoupling of responses. American Naturalist 152: 237-248. 
Buckley, B. A. \& A. M. Szmant, 2004. RNA/DNA ratios as indicators of metabolic activity in four species of Caribbean reef-building corals. Marine Ecology Progress Series 282: 143-149.

Černý, M. \& P. D. N. Hebert, 2011. How long live the clone? Temporal and spatial patterns of asexual Daphnia pulicaria distribution among alpine lakes. Book of Abstracts of the IX International Symposium on Cladocera, Verbania: 6 .

Cullen, M., R. S. Kaufmann \& M. S. Lowery, 2003. Seasonal variation in biochemical indicators of physiological status in Euphausia superba from Port Foster, Deception Island, Antarctica. Deep-Sea Research II 50: 1787-1798.

de Bernardi, R., 1984. Methods for the estimation of zooplankton abundance. In Downing, J. A. \& F. H. Rigler (eds), A Manual on Methods for the Assessment of Secondary Productivity in Fresh Waters (IBP Hand Book 17). Blackwell, London: 59-86.

Dawidowicz, P., P. Prędki \& B. Pietrzak, 2010. Shortened lifespan: another cost of fish-predator avoidance in cladocerans? Hydrobiologia 643: 27-32.

Dawidowicz, P., P. Prędki \& B. Pietrzak, 2012. Depth selection behavior and longevity in Daphnia: an evolutionary test for the predation-avoidance hypothesis. Hydrobiologia. doi: 10.1007/s10750-012-1393-5

Dufresne, F., S. Marková, R. Vergilino, M. Ventura \& P. Kotlík, 2011. Diversity in the reproductive modes of European Daphnia pulicaria deviates from the geographical parthenogenesis. PloS One 6: e20049.

Edmondson, W., 1955. The seasonal life history of Daphnia in an arctic lake. Ecology 36: 439-455.

Gillooly, J. F., J. H. Brown, G. B. West, V. M. Savage \& E. L. Charnov, 2001. Effects of size and temperature on metabolic rate. Science 293: 2248-2251.

Gliwicz, M. Z., A. Slusarczyk \& M. Slusarczyk, 2001. Life history synchronization in a long-lifespan single-cohort Daphnia population in a fishless alpine lake. Oecologia 128: 368-378.

Gliwicz, Z. M., 1990. Food thresholds and body size in cladocerans. Nature 343: 638-640.

Gorokhova, E. \& M. Kyle, 2002. Analysis of nucleic acids in Daphnia: development of methods and ontogenetic variations in RNA-DNA content. Journal of Plankton Research 24: 511-522.

Grime, J., 1977. Evidence for the existence of three primary strategies in plants and its relevance to ecological and evolutionary theory. American Naturalist 111: 1169-1194.

Houthoofd, K., B. P. Braeckman, I. Lenaerts, K. Brys, A. De Vreese, S. Van Eygen \& J. R. Vanfleteren, 2002. No reduction of metabolic rate in food restricted Caenorhabditis elegans. Experimental Gerontology 37: 1359-1369.

Ibiam, U. \& A. Grant, 2005. RNA/DNA ratios as a sublethal endpoint for large-scale toxicity tests with the nematode Caenorhabditis elegans. Environmental Toxicology and Chemistry 24: 1155-1159.

Kessler, K., 2004. Distribution of Daphnia in a trade-off between food and temperature: individual habitat choice and time allocation. Freshwater Biology 49: 1220-1229.

Kessler, K. \& W. Lampert, 2004. Depth distribution of Daphnia in response to a deep-water algal maximum: the effect of body size and temperature gradient. Freshwater Biology 49: 392-401.
Kozłowski, J., 1993. Measuring fitness in life history studies. Trends in Ecology and Evolution 8: 84-85.

Kreutzer, C., 1999. Threshold food concentration differences in differently sized Daphnia pulicaria: experimental evidence for a competitive bottleneck. Book of Abstracts of the 5th International Symposium on Cladocera, Ploen: 30.

Larsson, P. \& I. Wathne, 2006. Swim or rest during the winter what is best for an alpine daphnid? Archiv für Hydrobiologie 167: 265-280.

Leiser, S. F., A. Begun \& M. Kaeberlein, 2011. HIF-1 modulates longevity and healthspan in a temperature-dependent manner. Aging Cell 10: 318-326.

MacArthur, J. \& W. Baillie, 1929. Metabolic activity and duration of life. I. Influence of temperature on longevity in Daphnia magna. Journal of Experimental Zoology 53: 221-242.

Masson, S., B. Pinel-Alloul, G. Méthot \& N. Richard, 2004. Comparison of nets and pump sampling gears to assess zooplankton vertical distribution in stratified lakes. Journal of Plankton Research 26: 1199-1206.

McArthur, M. C. \& R. S. Sohal, 1982. Relationship between metabolic rate, aging, lipid peroxidation, and fluorescent age pigment in milkweed bug, Oncopeltus fasciatus (Hemiptera). Journal of Gerontology 37: 268-274.

Meesters, E., G. Nieuwland, G. Duineveld, A. Kok \& R. Bak, 2002. RNA/DNA ratios of scleractinian corals suggest acclimatisation/adaptation in relation to light gradients and turbidity regimes. Marine Ecology Progress Series 227: 233-239.

Minkiewicz, S., 1911. Przyczynek do zmienności sezonowej dwóch rozwielitek tatrzańskich (Contribution to the seasonal variation of two Daphnia from the Tatras). Kosmos 36: 383-394.

Miquel, J., P. R. Lundgren, K. G. Bensch \& H. Atlan, 1976. Effects of temperature on the life span, vitality and fine structure of Drosophila melanogaster. Mechanisms of Ageing and Development 5: 347.

Orcutt, J. D. \& K. G. Porter, 1984. The synergistic effects of temperature and food concentration of life history parameters of Daphnia. Oecologia 63: 300-306.

Pearl, R., 1928. The Rate of Living, Being an Account of Some Experimental Studies on the Biology of Life Duration. A. A. Knopf, New York.

Pianka, E. R., 1970. On r-and K-selection. American Naturalist 104: 592-597.

Pijanowska, J., P. Dawidowicz, A. Howe \& L. J. Weider, 2006. Predator-induced shifts in Daphnia life-histories under different food regimes. Archiv für Hydrobiologie 167: 37-54.

Reichwaldt, E. S., 2008. Food quality influences habitat selection in Daphnia. Freshwater Biology 53: 872-883.

Reichwaldt, E. S. \& G. Abrusán, 2007. Influence of food quality on depth selection of Daphnia pulicaria. Journal of Plankton Research 29: 839-849.

Ringelberg, J., 2010. Diel Vertical Migration of Zooplankton in Lakes and Oceans: Causal Explanations and Adaptive Significances. Springer, New York.

Rhode, S. C., M. Pawlowski \& R. Tollrian, 2001. The impact of ultraviolet radiation on the vertical distribution of zooplankton of the genus Daphnia. Nature 412: 69-72.

Slusarczyk, M., 2009. Extended lifespan traded for diapause in Daphnia. Freshwater Biology 54: 2252-2262. 
Sohal, R. S., R. J. Mockett \& W. C. Orr, 2002. Mechanisms of aging: an appraisal of the oxidative stress hypothesis. Free Radical Biology and Medicine 33: 575-586.

Speakman, J. R., 2005. Body size, energy metabolism and lifespan. Journal of Experimental Biology 208: 1717-1730.

Stearns, S. C., 1992. The Evolution of Life Histories. Oxford University Press, Oxford.

Stross, R. \& D. Kangas, 1969. The reproductive cycle of Daphnia in an arctic pool. Ecology 50: 457-460.

Tartarotti, B., S. Cabrera, R. Psenner \& R. Sommaruga, 1999. Survivorship of Cyclops abyssorum tatricus (Cyclopoida, Copepoda) and Boeckella gracilipes (Calanoida, Copepoda) under ambient levels of solar UVB radiation in two high-mountain lakes. Journal of Plankton Research 21: 549-560.

Threlkeld, S. T., 1979. The midsummer dynamics of two Daphnia species in Wintergreen Lake, Michigan. Ecology 60: 165-179.

Threlkeld, S. T., 1987. Daphnia life history strategies and resource allocation patterns. In Peters, R. H. \& R. de Bernardi (eds), Daphnia, Vol. 45. Memorie dell'Istituto Italiano di Idrobiologia, Pallanza: 353-366.

Vrede, T., J. Persson \& G. Aronsen, 2002. The influence of food quality (P:C ratio) on RNA:DNA ratio and somatic growth rate of Daphnia. Limnology and Oceanography 47: 487-494.

Wagner, M., E. Durbin \& L. Buckley, 1998. RNA:DNA ratios as indicators of nutritional condition in the copepod Calanus finmarchicus. Marine Ecology Progress Series 162: 173-181.

Welschmeyer, N. A., 1994. Fluorometric analysis of chlorophyll $a$ in the presence of chlorophyll $\mathrm{b}$ and pheopigments. Limnology and Oceanography 39: 1985-1992.

Wetzel, R. \& G. Likens, 1991. Limnological Methods. Springer, New York.

Wieser, W., G. Krumschnabel \& J. P. Ojwang-Okwor, 1992. The energetics of starvation and growth after refeeding in juveniles of three cyprinid species. Environmental Biology of Fishes 33: 63-71.

Williamson, C. E., O. G. Olson, S. E. Lott, N. D. Walker, D. R. Engstrom \& B. R. Hargreaves, 2001. Ultraviolet radiation and zooplankton community structure following deglaciation in Glacier Bay, Alaska. Ecology 82: 1748-1760.

Zhou, B. S., R. S. Wu, D. J. Randall \& P. K. Lam, 2001. Bioenergetics and RNA/DNA ratios in the common carp (Cyprinus carpio) under hypoxia. Journal of Comparative Physiology B 171: 49-57. 